\title{
Oilseed Meal Effects on the Emergence and Survival of Crop and Weed Species
}

\author{
Katie L. Rothlisberger, Frank M. Hons, Terry J. Gentry, and Scott A. Senseman \\ Department of Soil and Crop Sciences, Texas AઐM University, 370 Olsen Boulevard, 2474 TAMU, College Station, \\ TX 77843-2474, USA \\ Correspondence should be addressed to Katie L. Rothlisberger, krothlisberger@ag.tamu.edu
}

Received 28 October 2011; Revised 20 December 2011; Accepted 23 December 2011

Academic Editor: Philip White

Copyright ( $\odot 2012$ Katie L. Rothlisberger et al. This is an open access article distributed under the Creative Commons Attribution License, which permits unrestricted use, distribution, and reproduction in any medium, provided the original work is properly cited.

\begin{abstract}
Oilseed crops are being widely evaluated for potential biodiesel production. Seed meal (SM) remaining after extracting oil may have use as bioherbicides or organic fertilizers. Brassicaceae SM often contains glucosinolates that hydrolyze into biologically active compounds that may inhibit various pests. Jatropha curcas SM contains curcin, a phytoxin. A 14-day greenhouse study determined that Sinapis alba (white mustard), Brassica juncea (Indian mustard), Camelina sativa, and Jatropha curcas applied to soil at varying application rates $[0,0.5,1.0$, and $2.5 \%(\mathrm{w} / \mathrm{w})]$ and incubation times $(1,7$, and $14 \mathrm{~d})$ prior to planting affected seed emergence and seedling survival of cotton [Gossypium hirsutum (L.)], sorghum [Sorghum bicolor (L.) Moench], johnsongrass (Sorghum halepense), and redroot pigweed (Amaranthus retroflexus). With each species, emergence and survival was most decreased by 2.5\% SM application applied at 1 and $7 \mathrm{~d}$ incubations. White mustard SM incubated for $1 \mathrm{~d}$ applied at low and high rates had similar negative effects on johnsongrass seedlings. Redroot pigweed seedling survival was generally most decreased by all $2.5 \%$ SM applications. Based on significant effects determined by ANOVA, results suggested that the type, rate, and timing of SM application should be considered before land-applying SMs in cropping systems.
\end{abstract}

\section{Introduction}

Research involving oilseed crops for biodiesel production has increased due to greater needs for renewable energy sources. Biodiesel is an EPA-approved renewable fuel that can be produced from oilseed crops. The oil extracted from seed is chemically reacted with an alcohol, such as methanol, to form chemical compounds known as fatty acid methyl esters, or "biodiesel." The oil contained in the seed is most often extracted mechanically using a screw press. The residue remaining after oil extraction is referred to as either a press cake or seed meal (SM). In order for biodiesel production to be economically and environmentally sustainable, a feasible and profitable means of byproduct or SM disposal and/or usage needs to be developed. Utilization of SM in organic agricultural production systems offers a possible solution.

Oilseeds have the potential to produce significant energy and renewable fuels and include such oilseeds as soybean [Glycine $\max$ (L.) Merr.], canola and rapeseed (Brassica napus), Indian mustard (Brassica juncea), white mustard (Sinapis alba), physic nut or jatropha (Jatropha curcas), camelina (Camelina sativa), and castor bean (Ricinus communis). Brassicaceae oilseeds have been reported to contain 30 to $40 \%$ oil by weight [1], while jatropha seed contains a similar range of 30 to $37 \%$ [2]. Recent interest in jatropha is due primarily to its purported ability to grow on marginal lands. Therefore, its cultivation would be less likely to displace food-producing crops [3], but it is limited to subtropical and tropical environments. Jatropha and generally all oilseeds are rich in protein, containing a good balance of amino acids. The SM of jatropha reportedly contains more nutrients than either chicken or cattle manure [4].

Many oilseed meals, such as from soybean, have been used as additives in animal feed because of their high nutrient content, but certain plants within the Brassicaceae family cannot be used in the same manner because of their biocidal properties. Upon enzymatic hydration by myrosinase, a number of allelochemicals are produced in 
Brassicaceae SMs as secondary biologically active compounds of glucosinolates, which are $\beta$-thioglycosides with a sulphonated oxime moiety and a variable side-chain derived from amino acids [5]. Myrosinase is physically separated from the glucosinolates until the plant tissue is disrupted [6]. Glucosinolates are grouped as either aliphatic, aromatic, or indolyl based on the nature of their side chain or R group. Seed meals with individual side chains in combination with environmental conditions such as $\mathrm{pH}$, moisture levels, $\mathrm{Fe}^{2+}$ concentration, and the presence of coenzymes, determine which hydrolysis products will form. Allelochemical persistence and biocidal activity in soil will influence the ability of seed to germinate and survive. Potential allelochemicals include isothiocyanates (ITCs), ionic thiocyanates $\left(\mathrm{SCN}^{-}\right)$, nitriles, and oxazolidinediones (OZT).

Glucosinolate-containing SMs incorporated into soil have been reported to have possible herbicidal, insecticidal, nematicidal, and fungicidal effects [7]. A field study by Rice et al. [8] showed that white mustard, Indian mustard, and rapeseed SMs significantly reduced redroot pigweed (Amaranthus retroflexus L.) biomass by 59-93\% compared to the control. A greenhouse study by Ju et al. [9] reported that $\mathrm{SCN}^{-}$, liberated from white mustard $\mathrm{SM}$, inhibited the growth of tobacco (Nicotiana tabacum L. cv. Delhi 76) and bean (Phaseolus vulgaris L. cv. Contender). Though not in the mustard family, jatropha SM also contains toxic compounds such as curcin, a toxalbumin, and other equally negative substances such as phorbol esters [3]. Phorbol esters are the likely source of toxicity in jatropha. These compounds decompose rapidly, usually within days, as they are sensitive to light, elevated temperatures, and atmospheric oxygen [10].

Oilseed meals may potentially be applied to agricultural soils as sources of organic nutrients and/or organic pesticides. However, concerns arise from the harmful effects that crop species may experience from SMs used in this manner. The main objective of this paper was to determine the potential effects of white mustard, Indian mustard, camelina, and jatropha SMs added to soil at varying application rates and incubation times on the emergence and early survival of both crop and weed species.

\section{Materials and Methods}

2.1. Soil and SM Collection and Characterization. Greenhouse studies were conducted using soil collected from the Texas AgriLife Research and Extension Center near Overton, TX. Soil at this site is characterized as Darco loamy fine sand (loamy, siliceous, semiactive, thermic Grossarenic Paleudults) with a $\mathrm{pH}$ of 5.6. The soil was air dried for approximately 21 days, thoroughly mixed and stored until further use. This soil was chosen due to its sandy texture and low native fertility.

Oilseed species chosen for this study were Sinapis alba cv. Ida Gold (L.A. Hearne Seeds, Monterey County, CA), Brassica juncea cv. Pacific Gold (L.A. Hearne Seeds, Monterey County, CA), Jatropha curcas, and Camelina sativa (Texas Agrilife Research and Extension, College Station, TX). Jatropha fruit was dehulled by hand prior to seed pressing.
A motor-driven screw press operating at $95-100^{\circ} \mathrm{C}$ was used to extract the oil from seed. The oil constituted approximately $20-30 \%$ of the various seeds by weight, and approximately $90-95 \%$ of the total oil content was extracted. The SMs were stored at approximately $0^{\circ} \mathrm{C}$ until incorporation into soil. Both the soil and SMs were analyzed for total organic $\mathrm{C}$ and total $\mathrm{N}$ by a combustion procedure [11-13]. The soil was analyzed for extractable $\mathrm{P}, \mathrm{K}, \mathrm{Ca}, \mathrm{Mg}$, and $S$ by Mehlich III $[14,15]$ and analysis by ICP, and micronutrients $(\mathrm{Cu}, \mathrm{Fe}, \mathrm{Mn}$, and $\mathrm{Zn})$ by extraction with DTPA-TEA, followed by ICP analysis [16], and extractable $\mathrm{NO}_{3}-\mathrm{N}$ by cadmium reduction following extraction by $1 \mathrm{~N}$ $\mathrm{KCl}$ [17]. Mineral compositions of SM (B, Ca, Cu, Fe, $\mathrm{K}, \mathrm{Mg}, \mathrm{Mn}, \mathrm{Na}, \mathrm{P}, \mathrm{S}$, and $\mathrm{Zn}$ ) were determined by ICP analysis of nitric acid digests. Soil electrical conductivity (EC) was determined in a $1: 2$ soil-to-water extract using deionized water, with the actual determination made using a conductivity probe [18]. Soil texture was determined using the hydrometer procedure [19].

Glucosinolate concentrations of white mustard and jatropha were determined by high performance liquid chromatography (HPLC) using methods of two previous studies $[20,21]$ based on ISO 9167 [22] and quantified glucosinolate concentrations of Indian mustard and camelina SMs, respectively. Expected retention behavior, such as time and sequence, and absorption spectra were used to identify individual glucosinolate peaks. Sinigrin monohydrate (Science Lab, Houston, TX) was utilized as an internal standard to calculate the major glucosinolate concentration.

2.2. Experimental Design and Data Collection. An emergence and survival study was conducted in a temperaturecontrolled glasshouse using cotton [Gossypium hirsutum (L.)], sorghum [Sorghum bicolor (L.) Moench], johnsongrass (Sorghum halepense), and redroot pigweed (Amaranthus retroflexus) as the crop and weed species. The study was a complete factorial within a completely randomized design with four replications of 36 treatment combinations, including: SM type (white mustard, Indian mustard, camelina, and jatropha), application rate $[0.5,1.0$, and $2.5 \%$ on dry weight basis $(\mathrm{w} / \mathrm{w})]$, and incubation time $(1,7$, and $14 \mathrm{~d}$ prior to planting). Before mixing with soil, SMs were finely crushed using a mortar and pestle. Approximately $340 \mathrm{~g}$ of soil-SM mixture were added to $\sim 500$ - $\mathrm{mL}$ growth cups and incubated for the designated times at 32 to $35^{\circ} \mathrm{C}$ in the glass house. The soil was not disturbed other than at planting. The gravimetric water content of mixtures was kept constant at $0.24 \mathrm{gg}^{-1}$ by weighing and adding distilled water daily. Nonamended soil was used as the control treatment for each crop or weed species.

On 29 July 2009, ten sorghum or cotton, 50 redroot pigweed, or 100 johnsongrass viable seed were planted into each individual treatment replication. The actual number of seed planted was based on the average germination percentage of $100 \mathrm{crop} /$ weed seed, which was determined prior to the start of the experiment (data not shown). Counting of emerged seedlings began the first day following planting and continued on a daily basis for $14 \mathrm{~d}$. Seedlings were considered emerged when visible above the soil surface. 
TABLE 1: Total nutrient concentrations of oilseed meals and total C and N and extractable nutrients in Darco soil.

\begin{tabular}{|c|c|c|c|c|c|}
\hline \multirow{2}{*}{ Concentration } & \multirow{2}{*}{$\begin{array}{c}\text { Soil } \\
\text { Darco }\end{array}$} & \multicolumn{4}{|c|}{ Oilseed meal } \\
\hline & & White mustard & Indian mustard & Camelina & Jatropha \\
\hline $\mathrm{pH}$ & 5.6 & 5.0 & 6.0 & 6.6 & 7.0 \\
\hline Organic C (\%) & 0.37 & 49.17 & 50.35 & 44.88 & 47.58 \\
\hline Total N (\%) & 0.08 & 5.09 & 5.00 & 5.36 & 3.46 \\
\hline $\mathrm{C}: \mathrm{N}$ & 4.6 & 9.7 & 10.1 & 8.4 & 13.8 \\
\hline $\mathrm{NO}_{3}-\mathrm{N}\left(\mathrm{mg} \mathrm{kg}^{-1}\right)$ & 7.9 & - & - & - & - \\
\hline $\mathrm{P}\left(\mathrm{mg} \mathrm{kg}^{-1}\right)$ & 28 & 8848 & 11818 & 8695 & 8058 \\
\hline $\mathrm{K}\left(\mathrm{mg} \mathrm{kg}^{-1}\right)$ & 42 & 11014 & 11368 & 14978 & 15397 \\
\hline $\mathrm{Ca}\left(\mathrm{mg} \mathrm{kg}^{-1}\right)$ & 191 & 6341 & 6092 & 6832 & 11470 \\
\hline $\mathrm{Mg}\left(\mathrm{mg} \mathrm{kg}^{-1}\right)$ & 26 & 3473 & 4470 & 4270 & 4748 \\
\hline $\mathrm{S}\left(\mathrm{mg} \mathrm{kg}^{-1}\right)$ & 14 & - & - & - & - \\
\hline $\mathrm{Na}\left(\mathrm{mg} \mathrm{kg}^{-1}\right)$ & 97 & 493 & 588 & 550 & 1291 \\
\hline $\mathrm{Fe}\left(\mathrm{mg} \mathrm{kg}^{-1}\right)$ & 15.1 & 40.1 & 47.0 & 45.2 & 40.1 \\
\hline $\mathrm{Zn}\left(\mathrm{mg} \mathrm{kg}^{-1}\right)$ & 1.8 & 65.1 & 68.1 & 65.4 & 30.6 \\
\hline $\operatorname{Mn}\left(\mathrm{mg} \mathrm{kg}^{-1}\right)$ & 7.5 & 35.9 & 57.7 & 64.6 & 35.9 \\
\hline $\mathrm{Cu}\left(\mathrm{mg} \mathrm{kg}^{-1}\right)$ & 0.2 & 9.9 & 10.2 & 14.5 & 15.9 \\
\hline
\end{tabular}

On the 14th and final day of data collection, survival counts were made based on the number of viable seedlings present within each replicate. Viable seedlings were defined as having a well-developed root and shoot system and as being at a comparable or more mature growth stage relative to the controls.

2.3. Statistical Analysis. Relative emergence was calculated as the percentage of planted seed emerged in SM treatments relative to those emerged in controls. Relative survival was based on the number of viable seedlings in treatments as a percent of control seedlings. Statistical analysis was conducted using SAS version 9.2. The effects of main factors and their interactions on crop and weed emergence and survival were analyzed using a mixed analysis of variance (ANOVA) procedure at a significance level of $P<0.05$. Main and interaction means when significant were separated using Fisher's protected LSD.

\section{Results}

3.1. Soil and SM Characteristics. Results showed the Darco soil to be deficient in plant available $\mathrm{N}, \mathrm{P}, \mathrm{K}$, and $\mathrm{Mg}$. The soil was sufficient in $\mathrm{Ca}, \mathrm{S}$, and $\mathrm{Cu}$, and somewhat high to moderate in $\mathrm{Fe}, \mathrm{Zn}$, and $\mathrm{Mn}$ (Table 1). This sandy soil $(79.3 \%$ sand, $14.2 \%$ clay, and $6.5 \%$ silt $)$ exhibited an EC value of $37 \mu$ mhos $\mathrm{cm}^{-1}$; therefore, its salinity effects are negligible. Compositional analysis of SMs indicated that these materials may potentially supply significant amounts of nutrients for plant growth (Table 1). White mustard, Indian mustard, and camelina SMs had similar concentrations of total $\mathrm{C}$ and $\mathrm{N}$ (45 to $50 \%$ and $5 \%$, resp.). Total $\mathrm{N}$ was less in jatropha SM. Carbon: $\mathrm{N}$ ratios ranged from 8.4 to $10.1 \%$ for glucosinolate-containing SMs and was $13.8 \%$ for jatropha SM. Phosphorus concentration of Indian mustard SM was higher at $1.2 \%$ compared to the other three meals that averaged $0.9 \%$ P. Potassium concentration of jatropha SM was $1.5 \%$, which was greater than the average of the three remaining SMs at $1.3 \%$. Nutrient concentrations of SMs were comparable to values previously reported for Brassicaceae SMs to average $50 \% \mathrm{C}, 5.9 \% \mathrm{~N}$, and $1.3 \% \mathrm{P}$ by weight [1].

Glucosinolate extracts from SMs were utilized as an indicator of the potential biocidal activity that may be produced when Brassicaceae SMs are incorporated into soil. Other than jatropha, each SM in this study was determined to have its own individual glucosinolate profile. As mentioned previously, jatropha does not contain glucosinolates. The dominant glucosinolate compound found in white mustard SM was 4-hydroxybenzyl glucosinolate (glucosinalbin or sinalbin) at a concentration of $149.6 \mu \mathrm{molg}^{-1}$ on dry weight basis and a standard deviation of $2.3 \mu \mathrm{molg}^{-1}$. Indian mustard SM contained several compounds with the dominant one being 2-propenyl glucosinolate (sinigrin) at a concentration of $159.1 \pm 15.9 \mu \mathrm{mol} \mathrm{g}^{-1}$. These results correspond to those of Hansson et al. [7] and Rice et al. [8] who found the dominant compound contained in Indian mustard SM to be sinigrin at a concentration of 123.8 $\pm 15.3 \mu \mathrm{mol} \mathrm{g}^{-1}$ and $152.0 \pm 12.3 \mu \mathrm{mol} \mathrm{g}^{-1}$, respectively. Camelina SM contained three dominant compounds with the most prominent being 10-methylsufinyldecyl (12.2 \pm $7.5 \mu \mathrm{mol} \mathrm{g}^{-1}$ ) [21].

3.2. Effects on Johnsongrass. Within each main factor (SM source, application rate, and incubation time), observed effects were significant for both relative emergence and survival of johnsongrass (Table 2). Rate exhibited the most significant effect on emergence, while all three main effects were highly significant $(P<0.001)$ for survival. Camelina and white mustard SM resulted in significantly lower emergence $(78.8$ and $79.0 \%$, resp.) for johnsongrass compared with jatropha SM (91.0\%) (Figure 1). Johnsongrass in the $0.5 \%$ jatropha SM treatment had a relative emergence greater 
TABLE 2: ANOVA results for the main and interactive effects of seed meal source, application rate, and incubation time on cotton, sorghum, Johnsongrass, and pigweed emergence (emerg), and survival (surv). SM denotes seed meal source.

\begin{tabular}{lcccccrrr}
\hline \multirow{2}{*}{ Effect } & \multicolumn{2}{c}{ Cotton } & \multicolumn{2}{c}{ Sorghum } & \multicolumn{2}{c}{ Johnsongrass } & Pigweed \\
& emerg & surv & emerg & surv & emerg & surv & emerg & surv \\
& & & & & \multicolumn{2}{c}{$P$ value } & & \\
\hline SM & $<.0001$ & 0.0349 & 0.6148 & $<.0001$ & 0.0283 & $<.0001$ & 0.2307 & 0.0024 \\
Rate & $<.0001$ & $<.0001$ & $<.0001$ & $<.0001$ & $<.0001$ & $<.0001$ & $<.0001$ & $<.0001$ \\
SM $*$ Rate & 0.0541 & 0.2411 & 0.8481 & 0.0031 & 0.0315 & 0.0374 & 0.0899 & 0.0018 \\
Incubation & 0.1191 & $<.0001$ & 0.0266 & 0.007 & 0.0185 & $<.0001$ & $<.0001$ & $<.0001$ \\
SM $*$ Incubation & $<.0001$ & 0.0182 & 0.0009 & 0.1825 & 0.2107 & $<.0001$ & 0.0017 & 0.0095 \\
Rate $*$ Incubation & 0.0041 & 0.0001 & 0.0059 & 0.3865 & 0.0056 & 0.0285 & 0.0002 & 0.0715 \\
SM $*$ Rate $*$ Incubation & 0.3804 & 0.0433 & 0.0084 & 0.0428 & $<.0001$ & 0.0029 & 0.0978 & 0.0008 \\
\hline
\end{tabular}

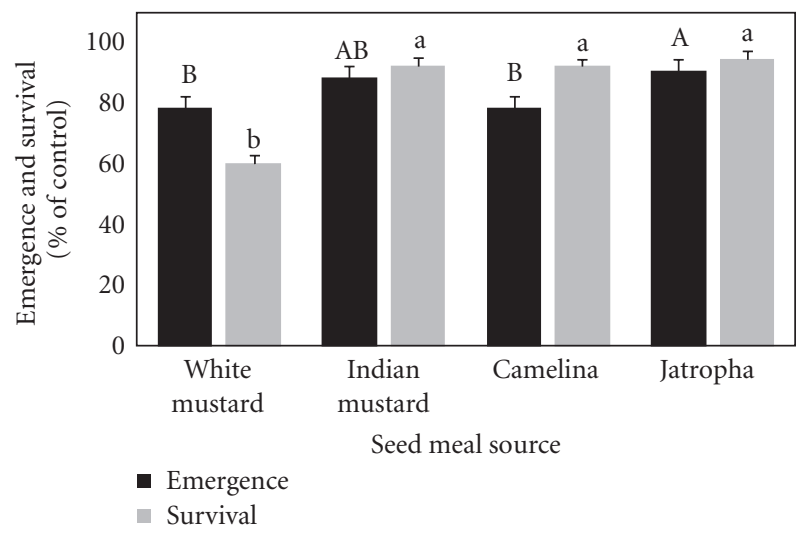

Figure 1: Main effect of "seed meal source" on Johnsongrass emergence and survival. Means within emergence or survival followed by the same letter are not different at $P<0.05$ by Fisher's protected LSD. Uppercase letters separate emergence means and lowercase letters separate survival means. Data are means (four replications) \pm SE.

than $100 \%(114 \%)$ because emergence in this treatment was greater than that of the control (Figure 2). This indicates that jatropha SM added at a rate of $0.5 \%$ does not cause injury, but does provide available nutrients for plant growth that the control does not.

Johnsongrass, redroot pigweed, cotton, and sorghum all showed significantly less emergence and survival with an SM application rate of 2.5\% (Figure 3). Relative survival of johnsongrass seedlings in white mustard treatments was also significantly less $(60.4 \%)$ than with any of the other three SMs (92.3-94.9\%) (Figure 1). Incubation time exhibited significantly different effects on relative emergence and survival of johnsongrass (Table 2). The $7 \mathrm{~d}$ incubation resulted in significantly less relative emergence than when incubated for $14 \mathrm{~d}$ (78.0 and $90.8 \%$, resp.), but not $1 \mathrm{~d}$ (84.5\%). However, the $1 \mathrm{~d}$ incubation did result in significantly less relative survival than either 7 or $14 \mathrm{~d}(67.0,91.9$, and $96.2 \%$, resp.) (data not shown).

Johnsongrass was more resistant than the two crops to phytotoxins in SMs, especially at higher application rates (Figure 3 ). The treatment combination that was most

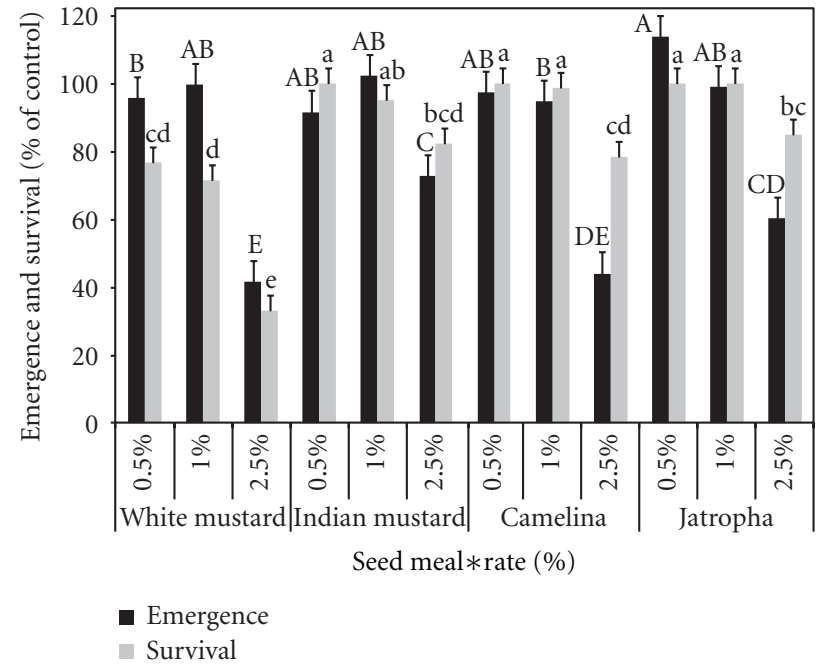

Figure 2: Interactive effects of "seed meal type and rate" on Johnsongrass emergence and survival. Means followed by the same letter are not different at $P<0.05$ by Fisher's protected LSD. Uppercase letters separate emergence means and lowercase letters separate survival means. Data are means (four replications) \pm SE.

effective at suppressing johnsongrass emergence was 2.5\% white mustard SM incubated for $7 \mathrm{~d}$ (16.4\%) and was significantly less than for any other treatment combination (Table 3). Seedling survival was most affected by $2.5 \%$ white mustard SM applied only $1 \mathrm{~d}$ prior to planting $(4.4 \%)$ (Table 3). The relative survival of johnsongrass seedlings with the latter treatment was significantly less than for any other treatment combination, other than $1.0 \%$ white mustard incubated 1 day (14.6\%). With a short period, such as $1 \mathrm{~d}$, between SM incorporation and seeding, there was sufficient time for $\mathrm{SCN}^{-}$production to reach toxic quantities from $1.0 \%$ white mustard SM to suppress johnsongrass growth. Therefore, if applied at correct timings, 1.0\% white mustard SM is as effective at suppressing johnsongrass as $2.5 \%$ white mustard SM.

3.3. Effects on Redroot Pigweed. Seed meal type did not affect relative emergence of redroot pigweed, but did significantly influence relative survival (Table 2). Camelina and 
TABLE 3: Three-way interaction of "seed meal source, application rate (applic) and incubation time (incub)" on johnsongrass and pigweed emergence (emerg) and survival (surv). Incubation refers to the length of time in days after SM was added to soil and prior to seeding. Data are the means (four replications) within weed species $(n=144)$.

\begin{tabular}{|c|c|c|c|c|c|c|}
\hline \multirow{3}{*}{ Seed meal } & \multirow{3}{*}{$\begin{array}{c}\text { Applic } \\
\%\end{array}$} & \multirow{3}{*}{$\begin{array}{c}\text { Incub } \\
\mathrm{d}\end{array}$} & \multicolumn{2}{|c|}{ Johnsongrass } & \multicolumn{2}{|c|}{ Pigweed } \\
\hline & & & Emerg & Surv & Emerg & Surv \\
\hline & & & \multicolumn{4}{|c|}{$\%$ of control } \\
\hline \multirow{9}{*}{ White mustard } & 0.5 & 1 & 83.2 & 30.1 & 103.5 & 97.4 \\
\hline & 0.5 & 7 & 85.5 & 100.0 & 48.4 & 96.4 \\
\hline & 0.5 & 14 & 118.5 & 100.0 & 109.8 & 100.0 \\
\hline & 1.0 & 1 & 83.2 & 14.6 & 29.8 & 81.3 \\
\hline & 1.0 & 7 & 117.3 & 100.0 & 6.3 & 18.8 \\
\hline & 1.0 & 14 & 98.3 & 100.0 & 25.5 & 75.0 \\
\hline & 2.5 & 1 & 74.0 & 4.4 & 7.0 & 18.8 \\
\hline & 2.5 & 7 & 16.4 & 28.1 & 0.0 & 0.0 \\
\hline & 2.5 & 14 & 34.5 & 66.5 & 0.0 & 0.0 \\
\hline \multirow{9}{*}{ Indian mustard } & 0.5 & 1 & 87.8 & 100.0 & 50.9 & 92.9 \\
\hline & 0.5 & 7 & 106.4 & 100.0 & 54.7 & 75.0 \\
\hline & 0.5 & 14 & 80.7 & 100.0 & 139.2 & 100.0 \\
\hline & 1.0 & 1 & 100.0 & 85.3 & 24.6 & 87.5 \\
\hline & 1.0 & 7 & 95.5 & 100.0 & 4.7 & 75.0 \\
\hline & 1.0 & 14 & 111.8 & 100.0 & 115.7 & 100.0 \\
\hline & 2.5 & 1 & 100.0 & 47.0 & 0.0 & 0.0 \\
\hline & 2.5 & 7 & 20.9 & 100.0 & 0.0 & 0.0 \\
\hline & 2.5 & 14 & 97.5 & 100.0 & 49.0 & 100.0 \\
\hline \multirow{9}{*}{ Jatropha } & 0.5 & 1 & 95.4 & 100.0 & 45.6 & 90.2 \\
\hline & 0.5 & 7 & 127.3 & 100.0 & 101.6 & 100.0 \\
\hline & 0.5 & 14 & 118.5 & 100.0 & 133.3 & 100.0 \\
\hline & 1.0 & 1 & 109.9 & 100.0 & 17.5 & 75.0 \\
\hline & 1.0 & 7 & 83.6 & 100.0 & 29.7 & 75.0 \\
\hline & 1.0 & 14 & 103.4 & 100.0 & 156.9 & 100.0 \\
\hline & 2.5 & 1 & 52.7 & 59.2 & 0.0 & 0.0 \\
\hline & 2.5 & 7 & 74.5 & 100.0 & 0.0 & 0.0 \\
\hline & 2.5 & 14 & 53.8 & 95.3 & 0.0 & 0.0 \\
\hline \multirow{9}{*}{ Camelina } & 0.5 & 1 & 91.6 & 100.0 & 108.8 & 100.0 \\
\hline & 0.5 & 7 & 83.6 & 100.0 & 40.6 & 90.8 \\
\hline & 0.5 & 14 & 116.8 & 100.0 & 172.5 & 100.0 \\
\hline & 1.0 & 1 & 96.9 & 95.8 & 15.8 & 29.2 \\
\hline & 1.0 & 7 & 90.0 & 100.0 & 4.7 & 25.0 \\
\hline & 1.0 & 14 & 97.5 & 100.0 & 98.0 & 95.0 \\
\hline & 2.5 & 1 & 38.9 & 67.9 & 0.0 & 0.0 \\
\hline & 2.5 & 7 & 34.5 & 75.0 & 0.0 & 0.0 \\
\hline & 2.5 & 14 & 58.8 & 92.3 & 0.0 & 0.0 \\
\hline $\mathrm{LSD}_{0.05}$ & & & 30.7 & 23.0 & NS & 33.7 \\
\hline
\end{tabular}

white mustard SMs significantly reduced redroot pigweed survival compared with Indian mustard (48.9, 54.2, and $70.1 \%$, resp.) (Figure 4). Redroot pigweed seed and seedlings were extremely sensitive to SM treatments applied at $2.5 \%$ (Table 2, Figure 3). Incubation times of 1 and $7 \mathrm{~d}$ produced significantly lower relative emergence and survival percentages relative to $14 \mathrm{~d}$ (33.6, 24.2, and $83.3 \%$ emergence, respectively, and 56.0, 46.3, and $72.5 \%$ survival, resp.) (Figure 5). Relative emergence and survival were $0 \%$ for all $2.5 \%$ treatments, with the exception of Indian mustard incubated for $14 \mathrm{~d}$ (49.0\% emergence and $100 \%$ survival) and white mustard incubated for $1 \mathrm{~d}(7.0 \%$ emergence and $18.8 \%$ survival) (Table 3 ). Numerically, relative survival of seedlings in treatments of $2.5 \%$ white mustard applied $1 \mathrm{~d}$ 


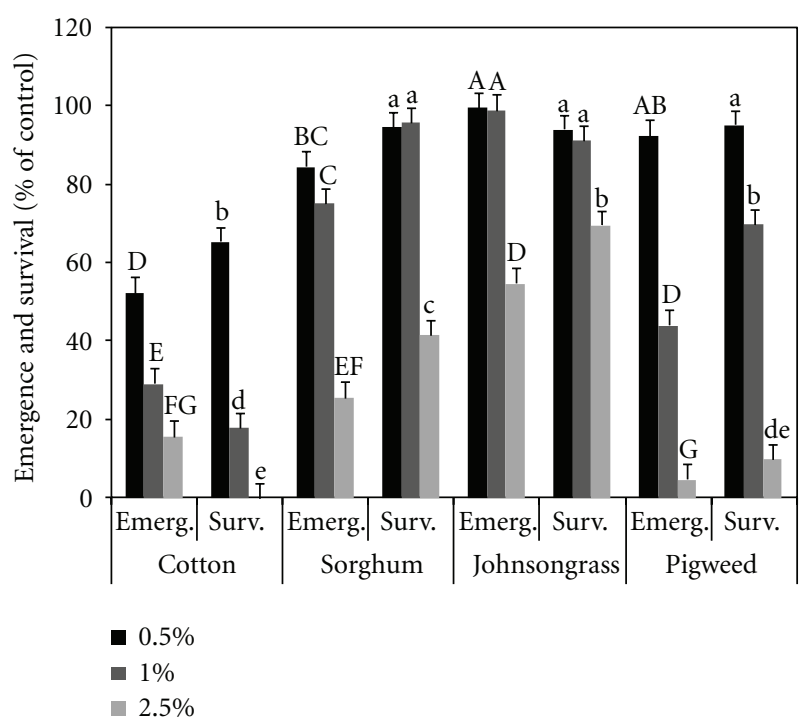

FIGURE 3: Seed meal rate effect on cotton, sorghum, Johnsongrass, and pigweed emergence and survival. Means followed by the same letter are not different at $P<0.05$ by Fisher's protected LSD. Uppercase letters separate emergence means and lowercase letters separate survival means. Data are means (four replications) \pm SE.

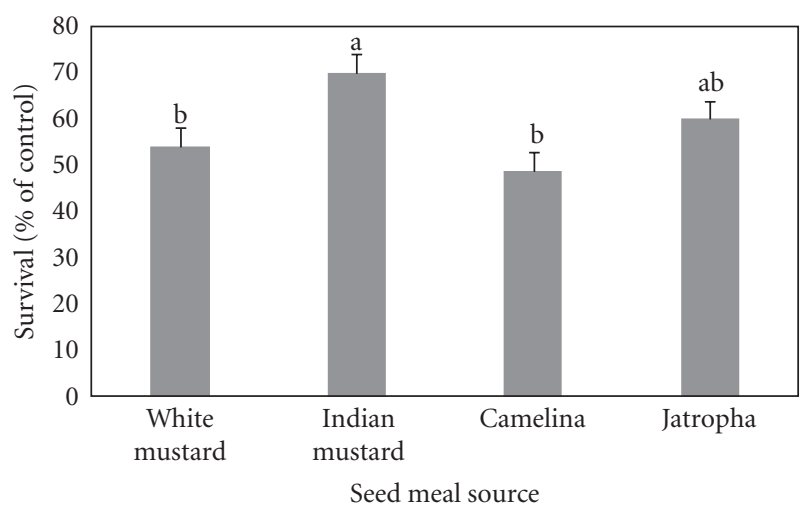

Figure 4: Main effect of "seed meal source" on pigweed survival. Means followed by the same letter are not different at $P<0.05$ by Fisher's protected LSD. The effect of "seed meal source" was not significant for pigweed emergence; therefore, data is not shown. Data are means (four replications) \pm SE.

before planting was higher than all other $2.5 \%$ treatments, but statistically there were no significant differences for any of the test plants (Tables 2 and 3 ).

3.4. Effects on Cotton. Of the three main effects, incubation time was the only one that did not show significant treatment effects on emergence of cotton seed (Table 2). Camelina SM resulted in significantly lower emergence (15.7\%) than white mustard (51.4\%) and jatropha (35.5\%), but not Indian mustard (26.9\%) (Figure 6). Seedling survival showed somewhat different results, with camelina treatments showing numerically the lowest survival (17.1\%), but being only significantly less compared to treatments with jatropha

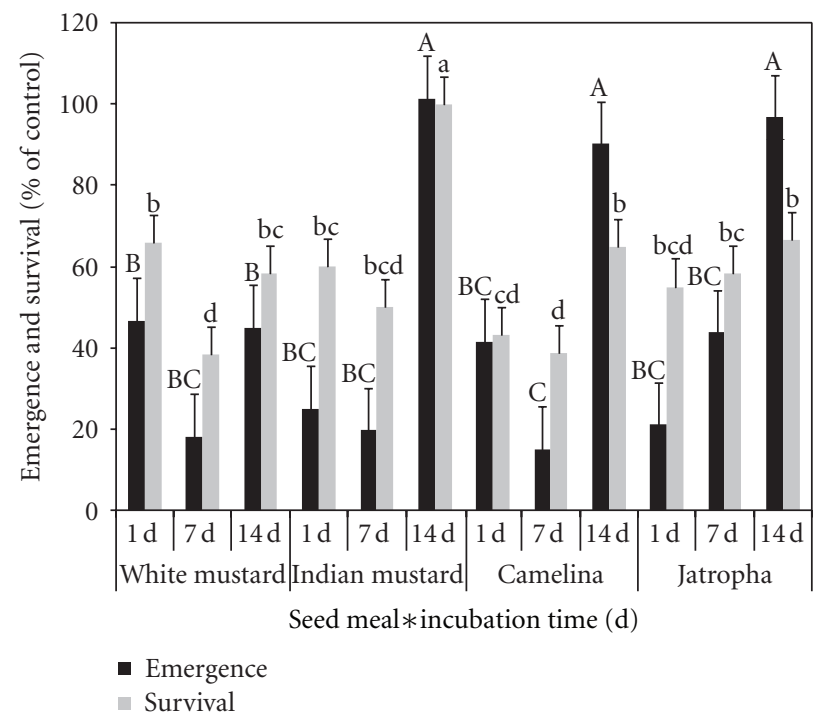

FIGURE 5: Interactive effects of "seed meal source and incubation time" on pigweed emergence (uppercase letters) and survival (lowercase letters). Means within emergence or survival followed by the same letter are not different at $P<0.05$ by Fisher's protected LSD. Data are means (four replications) \pm SE.

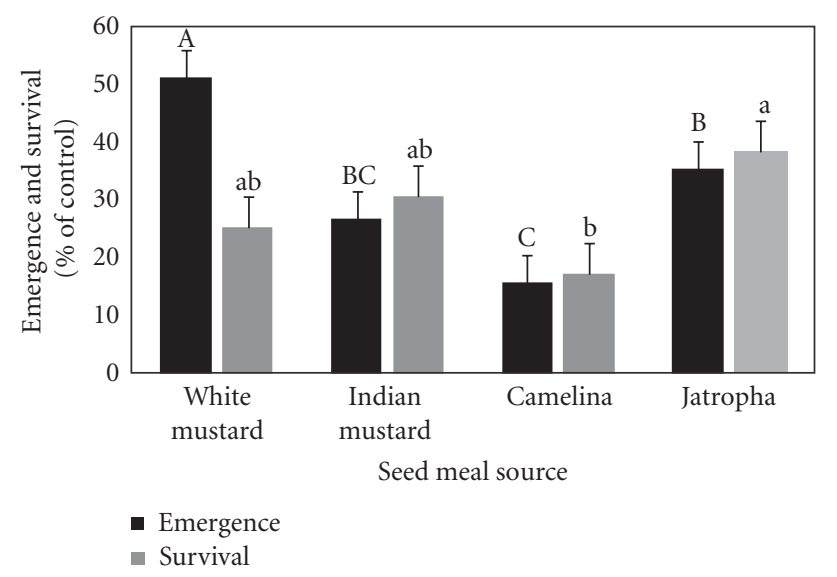

Figure 6: Main effect of "seed meal source" on cotton emergence (uppercase letters) and survival (lowercase letters). Means within emergence or survival followed by the same letter are not different at $P<0.05$ by Fisher's protected LSD. Data are means (four replications) \pm SE.

(38.3\%), which resulted in the highest survival percentage (Figure 6).

As with both weed species, treatment combinations including $2.5 \%$ SM exhibited significantly reduced seedling emergence and survival (Table 2, Figure 3). Incubation time significantly altered seedling survival, but not emergence (Table 2). One day incubation prior to planting had the most negative impact on seedling survival, but not emergence (Figure 7). The longer incubation time of $14 \mathrm{~d}$ increased average seedling survival to $46.4 \%$, but relative emergence was still only $31.9 \%$ for this incubation treatment. This result 


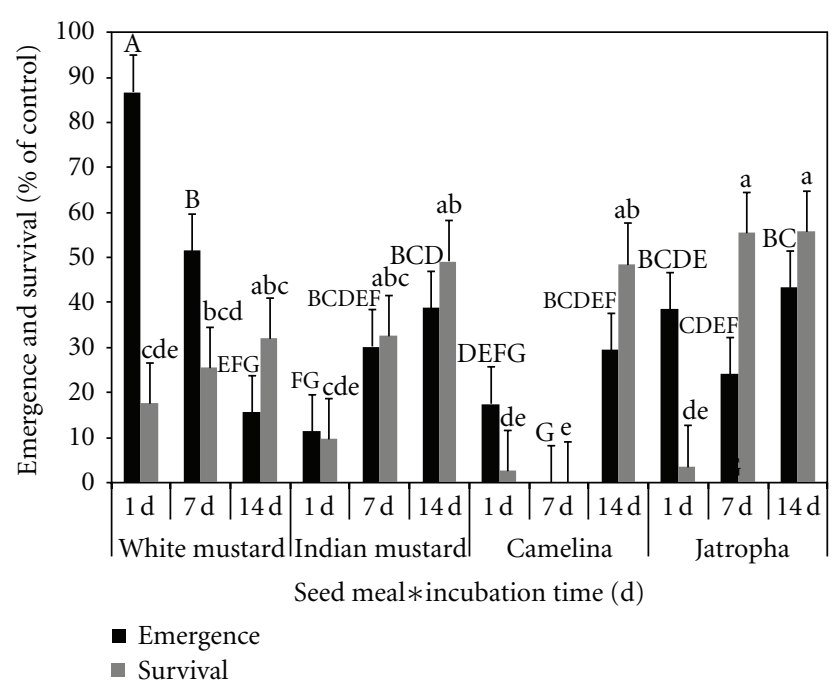

Figure 7: Interactive effect of "seed meal source and incubation time" on cotton emergence and survival. Emergence (uppercase letters) or survival (lowercase letters) means followed by the same letter are not different at $P<0.05$ by Fisher's protected LSD. Data are means (four replications) $\pm \mathrm{SE}$.

likely indicates the necessity for SM incubation longer than $14 \mathrm{~d}$ prior to planting cotton.

The two-way interaction of "seed meal source and application rate" was not significant for either relative emergence or survival of cotton (Table 2). From the twoway interaction of "seed meal source and incubation time" (Table 2, Figure 7), which was significant for both emergence and survival, rates of glucosinolate hydrolysis might be inferred. Hydrolysis of glucosinolates in white mustard SM based on emergence apparently increased over the incubation period, decreased with Indian mustard, and showed greatest toxicity at $7 \mathrm{~d}$ for camelina. White mustard SM applied $1 \mathrm{~d}$ prior to planting resulted in the highest emergence rate $(86.8 \%)$ relative to other treatments, but the survival rate of the seedlings was poor (17.7\%) (Figure 7). Longer incubation periods of white mustard SM resulted in decreased emergence, but increased seedling survival. The most negative effects on cotton emergence and survival with Indian mustard SM were observed with $1 \mathrm{~d}$ incubation (11.4\% emergence and 9.8\% survival), while camelina and jatropha SMs were most detrimental at $7 \mathrm{~d}$ incubation (Figure 7).

The three-way interaction of "seed meal source, application rate, and incubation time" was not significant for cotton emergence, and only slightly for survival (Table 2). White mustard applied at $2.5 \%$ and incubated for $1 \mathrm{~d}$ resulted in significantly higher cotton emergence $(94.7 \%)$ compared to any other treatment containing of $2.5 \%$ SM (0 to 36.8\%) (Table 4). Relative survival of seedlings in this treatment, however, failed to be significantly different than white mustard added at $2.5 \%$ and incubated for 7 or $14 \mathrm{~d}$. Seed of certain species, especially cotton and sorghum, sometimes emerged, but did not survive. The treatment most effective at suppressing johnsongrass and redroot pigweed growth,

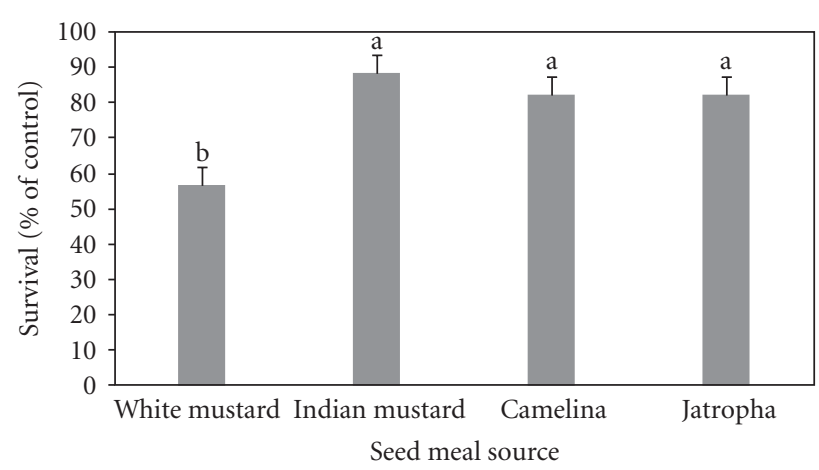

Figure 8: Main effect of "seed meal source" on sorghum survival. Means followed by the same letter are not different at $P<0.05$ by Fisher's protected LSD. The effect of "seed meal source" was not significant for sorghum emergence; therefore, the data is not shown. Data are means (four replications) \pm SE.

$2.5 \%$ white mustard SM at 1 or $7 \mathrm{~d}$ incubation (Table 3 ), also resulted in $0 \%$ survival of cotton seedlings (Table 4 ).

3.5. Effects on Sorghum. Of the three main effects, SM source was the only one not significant for sorghum emergence, but all three were significant for seedling survival (Table 2). Sorghum seedling survival was significantly less when treated with white mustard SM $(56.6 \%)$ relative to all other SMs (82.1\% to $88.3 \%$ ) (Figure 8). Application of $2.5 \%$ SM resulted in both significantly reduced emergence and seedling survival (25.6 and $41.5 \%$, resp.) compared to other rates ( 75.1 to $84.6 \%$ emergence and 94.8 to $95.8 \%$ survival) (Figure 3).

The three-way interaction was significant for both relative emergence and survival (Table 2). As with cotton, emergence of sorghum planted in treatments with white mustard SM decreased with increasing incubation time, while survival increased from 1 to $7 \mathrm{~d}$ of incubation (Figure 9, Table 4). White mustard SM at 2.5\% and $1 \mathrm{~d}$ incubation had significantly greater relative emergence $(75.9 \%)$ than any other $2.5 \%$ SM treatment combination (2.9 to $45.7 \%$ ) (Table 4). No treatment combinations were able to completely inhibit emergence, but all treatments containing $2.5 \%$ white mustard SM resulted in $0 \%$ relative survival of sorghum (Table 4).

\section{Discussion}

The use of oilseed meals as soil amendments has several potential benefits, but there are also possible detriments. Primarily, SMs might serve to replenish soil organic matter (SOM) in cropping systems where, for instance, stover has been removed for use as biofuel feedstocks. Used in this manner, meals from certain oilseeds have the potential to add significant organic $\mathrm{C}$ and nutrients to soil, while controlling or inhibiting weed growth. Our results suggest that in order to suppress weeds, white mustard SM should be applied at rates between 1 and $2.5 \%$, which will also supply a substantial amount of $\mathrm{N}$ (1120 to $\left.2800 \mathrm{~kg} \mathrm{~N} \mathrm{ha}^{-1}\right)$. Wang et al. [20] reported $3035 \mathrm{~kg} \mathrm{~N} \mathrm{ha}^{-1}$ and $4263 \mathrm{~kg} \mathrm{~N} \mathrm{ha}^{-1}$ 
TABle 4: Three-way interaction of "seed meal source, application rate (applic), and incubation time (incub)" on cotton and sorghum emergence (emerg) and survival (surv). Incubation refers to the length of time in days after SM was added to soil and prior to seeding. Data are the means (four replications) within crop species $(n=144)$.

\begin{tabular}{|c|c|c|c|c|c|c|}
\hline \multirow{3}{*}{ Seed meal } & \multirow{3}{*}{$\begin{array}{c}\text { Applic } \\
\%\end{array}$} & \multirow{3}{*}{$\begin{array}{c}\text { Incub } \\
\mathrm{d}\end{array}$} & \multicolumn{2}{|c|}{ Cotton } & \multicolumn{2}{|c|}{ Sorghum } \\
\hline & & & Emerg & Surv & Emerg & Surv \\
\hline & & & \multicolumn{4}{|c|}{$\%$ of control } \\
\hline \multirow{9}{*}{ White mustard } & 0.5 & 1 & 76.3 & 48.9 & 106.9 & 46.3 \\
\hline & 0.5 & 7 & 72.7 & 70.5 & 88.5 & 100.0 \\
\hline & 0.5 & 14 & 33.3 & 67.0 & 60.0 & 96.4 \\
\hline & 1.0 & 1 & 89.5 & 4.1 & 62.1 & 66.3 \\
\hline & 1.0 & 7 & 59.1 & 6.4 & 73.1 & 100.0 \\
\hline & 1.0 & 14 & 13.9 & 29.2 & 65.7 & 100.0 \\
\hline & 2.5 & 1 & 94.7 & 0.0 & 75.9 & 0.0 \\
\hline & 2.5 & 7 & 22.7 & 0.0 & 3.8 & 0.0 \\
\hline & 2.5 & 14 & 0.0 & 0.0 & 2.9 & 0.0 \\
\hline \multirow{9}{*}{ Indian mustard } & 0.5 & 1 & 26.3 & 29.3 & 69.0 & 100.0 \\
\hline & 0.5 & 7 & 90.9 & 97.8 & 100.0 & 100.0 \\
\hline & 0.5 & 14 & 75.0 & 108.8 & 94.3 & 94.4 \\
\hline & 1.0 & 1 & 5.3 & 0.0 & 72.4 & 100.0 \\
\hline & 1.0 & 7 & 0.0 & 0.0 & 103.8 & 100.0 \\
\hline & 1.0 & 14 & 25.0 & 38.9 & 68.6 & 100.0 \\
\hline & 2.5 & 1 & 2.6 & 0.0 & 13.8 & 50.0 \\
\hline & 2.5 & 7 & 0.0 & 0.0 & 26.9 & 50.0 \\
\hline & 2.5 & 14 & 16.7 & 0.0 & 45.7 & 100.0 \\
\hline \multirow{9}{*}{ Jatropha } & 0.5 & 1 & 34.2 & 10.9 & 65.5 & 100.0 \\
\hline & 0.5 & 7 & 45.5 & 128.2 & 103.8 & 100.0 \\
\hline & 0.5 & 14 & 75.0 & 99.8 & 71.4 & 100.0 \\
\hline & 1.0 & 1 & 44.7 & 0.0 & 75.9 & 100.0 \\
\hline & 1.0 & 7 & 27.3 & 38.5 & 76.9 & 100.0 \\
\hline & 1.0 & 14 & 55.6 & 67.6 & 80.0 & 100.0 \\
\hline & 2.5 & 1 & 36.8 & 0.0 & 34.5 & 20.8 \\
\hline & 2.5 & 7 & 0.0 & 0.0 & 38.5 & 68.8 \\
\hline & 2.5 & 14 & 0.0 & 0.0 & 5.7 & 50.0 \\
\hline \multirow{9}{*}{ Camelina } & 0.5 & 1 & 28.9 & 8.2 & 93.1 & 100.0 \\
\hline & 0.5 & 7 & 0.0 & 0.0 & 76.9 & 100.0 \\
\hline & 0.5 & 14 & 69.4 & 116.6 & 85.7 & 100.0 \\
\hline & 1.0 & 1 & 10.5 & 0.0 & 62.1 & 83.3 \\
\hline & 1.0 & 7 & 0.0 & 0.0 & 103.8 & 100.0 \\
\hline & 1.0 & 14 & 19.4 & 29.2 & 57.1 & 100.0 \\
\hline & 2.5 & 1 & 13.2 & 0.0 & 37.9 & 58.3 \\
\hline & 2.5 & 7 & 0.0 & 0.0 & 3.8 & 25.0 \\
\hline & 2.5 & 14 & 0.0 & 0.0 & 17.1 & 75.0 \\
\hline $\mathrm{LSD}_{0.05}$ & & & NS & 43.6 & 32.1 & 34.2 \\
\hline
\end{tabular}

present in soil after $51 \mathrm{~d}$ of incubation with mustard SM $(6.1 \% \mathrm{~N})$ applied at a rate of 1.0 and $2.5 \%$, respectively. Nitrogen applied in excess to soils and not synchronous with plant uptake may be lost from the system and could pose significant environmental risks. Seed meals applied at appropriate rates contain nutrient concentrations capable of potentially enhancing the productivity of low nutrient soils.
The absence of differences in $\mathrm{C}: \mathrm{N}$ ratios of glucosinolate containing SMs and the low buffering capacity of Darco soil suggests that there should be no confounding allelopathic effects on emergence and/or survival. As mentioned above, white mustard SM applied to soil at 2.5\% and incubated for 1 or $7 \mathrm{~d}$ prior to planting was most inhibitory to johnsongrass, which was the more difficult of the two weeds to control. 


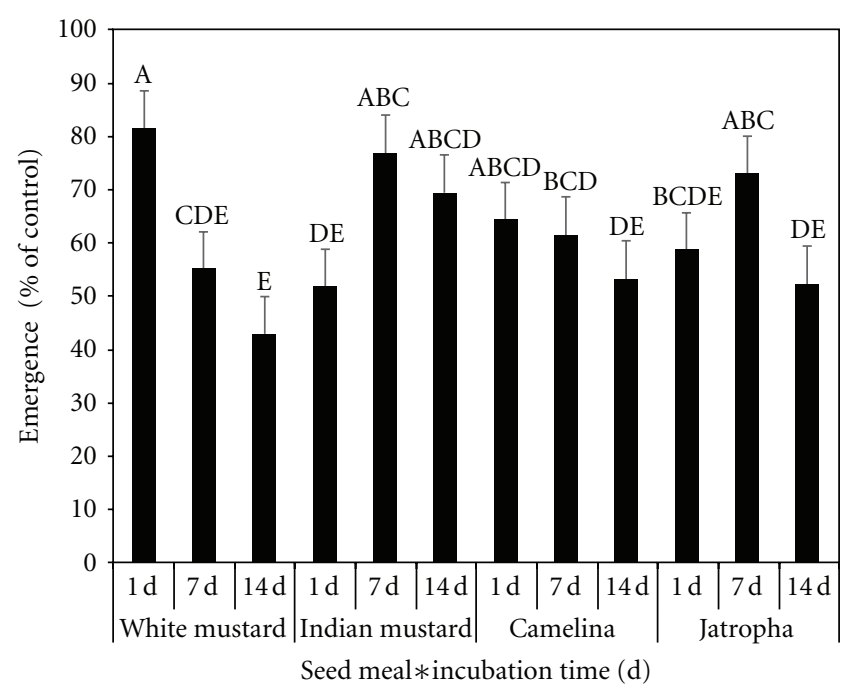

Figure 9: Interactive effect of "seed meal source and incubation time" on sorghum emergence. Emergence means followed by the same letter are not different at $P<0.05$ by Fisher's protected LSD. Interaction effects on sorghum survival were not significant $(P=0.1825)$; therefore, the data is not shown. Data are means (four replications) \pm SE.

While relative emergence of johnsongrass was significantly higher in treatments of " $1 \%$ white mustard incubated for $1 \mathrm{~d}$ " compared to the most inhibitory treatment, relative survival of seedlings in this treatment failed to be significantly different than with the $2.5 \% \mathrm{SM}$ application. It is likely that an application rate ranging from 1 to $2.5 \% \mathrm{SM}$ would be adequate to suppress johnsongrass growth.

Redroot pigweed emergence and survival was suppressed by all SM treatments of $2.5 \%$, excluding Indian mustard SM incubated for $14 \mathrm{~d}$. It is hypothesized that after $14 \mathrm{~d}$ of incubation the toxicity associated with Indian mustard SM dissipated sufficiently so that its inhibitory effects were reduced compared to other SMs. These results are in contrast to results reported by Rice et al. [8], who found that Indian mustard SM applied at 3\% was the only SM of the three studied (white mustard, Indian mustard, and rapeseed) to suppress redroot pigweed biomass compared to the no-meal treatment.

The treatment combination of " $2.5 \%$ white mustard SM with 7 or $14 \mathrm{~d}$ incubation" prior to planting was extremely detrimental to cotton and sorghum in our study, indicating that this SM likely must be incubated for a longer period of time before planting agricultural crops. Previous studies have shown the phytotoxin associated with white mustard, $\mathrm{SCN}^{-}$, decreased to almost background concentrations after $44 \mathrm{~d}$ at an application rate of $2 \mathrm{tha}^{-1}$ [7]. Phytotoxin dissipation in soil is highly dependent on SM application rates, soil water concentration, microbial activity, glucosinolate release efficiency, and rate of reaction.

Due to the decrease in cotton seed emergence from 1 to $14 \mathrm{~d}$ of incubation when planted in white mustard SM treatments, the rate of white mustard glucosinolate hydrolysis was assumed to be slower relative to the other
SMs. Glucosinolates in Indian mustard SM may have had the fastest rate of reaction since cotton seed emergence was lowest for treatments with 1 day incubation. Isothiocyanate concentrations of Indian mustard and rapeseed tissues have been shown to be highest $24 \mathrm{hrs}$ after incorporation and then dropping to less than half of the maximum in $72 \mathrm{hrs}$ [23]. Other studies have reported $\mathrm{SCN}^{-}$to have a longer half-life in soil compared with 2-propenyl isothiocyanate, the major phytotoxin produced from Indian mustard [24, 25]. Research has further shown that $60 \%$ of $\mathrm{SCN}^{-}$remained after 6 days [25], whereas the average half-life of 2-propenyl ITC in six different soils was $48 \mathrm{~h}$ [24]. The rate of glucosinolate hydrolysis and ITC persistence are dependent on many soil and environmental factors and for this reason are somewhat unpredictable, but they appear to be a feasible means of determining the point at which phytotoxins are at maximum concentrations and consequently, most detrimental to plant viability.

\section{Conclusion}

Mechanical weed control is a commonly used practice in organic farming systems but is not always feasible, successful, or economical. This study demonstrated the ability of oilseed meals to suppress and, in some cases, control johnsongrass and redroot pigweed by as much as $96 \%$. While weed suppression is achievable, factors such as soil characteristics, SM source, application rate, and incubation time prior to planting agronomic crops must be optimized to control weeds without damaging crops. The more nominal and practical SM application rate of $0.5 \%$ was much less effective in suppressing weeds compared to higher rates, especially $2.5 \%$. Rates of SM needed to effectively control weeds, however, may also supply very large quantities of nutrients, particularly $\mathrm{N}$, that could have negative environmental consequences. Further research, including but not limited to plant injury, crop yield, mammalian toxicology isothiocyanate, isothiocyanate biological activity, and soil persistence, is needed before SMs can be routinely recommended for organic production systems.

\section{References}

[1] A. Snyder, M. J. Morra, J. Johnson-Maynard, and D. C. Thill, "Seed meals from brassicaceae oilseed crops as soil amendments: influence on carrot growth, microbial biomass nitrogen, and nitrogen mineralization," HortScience, vol. 44, no. 2, pp. 354-361, 2009.

[2] G. R. Rao, G. R. Korwar, A. K. Shanker, and Y. S. Ramakrishna, "Genetic associations, variability and diversity in seed characters, growth, reproductive phenology and yield in Jatropha curcas (L.) accessions," Trees, vol. 22, no. 5, pp. 697-709, 2008.

[3] A. J. King, W. He, J. A. Cuevas, M. Freudenberger, D. Ramiaramanana, and I. A. Graham, "Potential of Jatropha curcas as a source of renewable oil and animal feed," Journal of Experimental Botany, vol. 60, no. 10, pp. 2897-2905, 2009.

[4] G. Francis, R. Edinger, and K. Becker, "A concept for simultaneous wasteland reclamation, fuel production, and socio-economic development in degraded areas in India: need, 
potential and perspectives of Jatropha plantations," Natural Resources Forum, vol. 29, no. 1, pp. 12-24, 2005.

[5] R. F. Mithen, "Glucosinolates and their degradation products," Advances in Botanical Research, vol. 35, pp. 213-232, 2001.

[6] A. L. Gimsing and J. A. Kirkegaard, "Glucosinolates and biofumigation: fate of glucosinolates and their hydrolysis products in soil," Phytochemistry Reviews, vol. 8, no. 1, pp. 299-310, 2009.

[7] D. Hansson, M. J. Morra, V. Borek, A. J. Snyder, J. L. Johnson-Maynard, and D. C. Thill, "Ionic thiocyanate (SCN-) production, fate, and phytotoxicity in soil amended with Brassicaceae seed meals," Journal of Agricultural and Food Chemistry, vol. 56, no. 11, pp. 3912-3917, 2008.

[8] A. R. Rice, J. L. Johnson-Maynard, D. C. Thill, and M. J. Morra, "Vegetable crop emergence and weed control following amendment with different," Renewable Agriculture and Food Systems, vol. 22, no. 3, pp. 204-212, 2007.

[9] H. Y. Ju, B. B. Bible, and C. Chong, "Influence of ionic thiocyanate on growth of cabbage, bean, and tobacco," Journal of Chemical Ecology, vol. 9, no. 8, pp. 1255-1262, 1983.

[10] R. E. E. Jongschaap, W. J. Corré, P. S. Bindraban, and W. A. Brandenburg, Claims and Facts on Jatropha Curcas L., Plant Research International, Wageningen, The Netherlands, 2007.

[11] S. L. McGeehan and D. V. Naylor, "Automated instrumental analysis of carbon and nitrogen in plant and soil samples," Communications in Soil Science \& Plant Analysis, vol. 19, no. 4, pp. 493-505, 1988.

[12] E. E. Schulte and B. G. Hopkins, "Estimation of soil organic matter by weight lost-on-ignition," in Soil Organic Matter: Analysis and Interpretation, F. R. Magdoff, M. A. Tabatabai, and E. A. Hanlon Jr., Eds., Special Publication No. 46, pp. 2132, Soil Science Society of America, Madison, Wis, USA, 1996.

[13] D. A. Storer, "A simple high sample volume ashing procedure for determination of soil organic matter," Communications in Soil Science \& Plant Analysis, vol. 15, no. 7, pp. 759-772, 1984.

[14] A. Mehlich, "New extractant for soil test evaluation of phosphorus, potassium, magnesium, calcium, sodium, manganese, and zinc," Communications in Soil Science and Plant Analysis, vol. 9, pp. 477-492, 1978.

[15] A. Mehlich, "Mehlich 3 soil test extractant: a modification of Mehlich 2 extractant," Communications in Soil Science \& Plant Analysis, vol. 15, no. 12, pp. 1409-1416, 1984.

[16] W. L. Lindsay and W. A. Norvell, "Development of a DTPA soil test for zinc, iron, manganese, and copper," Soil Science Society of America Journal, vol. 42, pp. 421-428, 1978.

[17] D. R. Keeney and D. W. Nelson, "Nitrogen-inorganic forms," in Methods of Soil Analysis, Part 2, A. L. Page et al., Ed., pp. 643-687, ASA and SSSA, Madison, Wis, USA, 1982.

[18] J. D. Rhoades, "Soluble salts," in Methods of Soil Analysis, Part 2, A. L. Page et al., Ed., pp. 167-168, ASA and SSSA, Madison, Wis, USA, 1982.

[19] P. R. Day, "Particle fractionation and particle-size analysis," in Methods of Soil Analysis, Part 1, C. A. Black et al., Ed., pp. 545567, ASA and SSSA, Madison, Wis, USA, 1965.

[20] A. S. Wang, P. Hu, E. B. Hollister et al., "Impact of Indian mustard (Brassica juncea) and flax (Linum usitatissimum) seed meal applications on soil carbon, nitrogen, and microbial dynamics," Applied and Environmental Soil Science, vol. 2012, Article ID 351609, 14 pages, 2012.

[21] P. Hu, A. S. Wang, A. S. Engledow et al., "Inhibition of the germination and growth of Phymatotrichopsis omnivora (Cotton root rot) by oilseed meals and isothiocyanates," Applied Soil Ecology, vol. 49, pp. 68-75, 2011.
[22] International Organization for Standarization, RapeseedDetermination of Glucosinolates Content-part 1: Method Using High-Performance Liquid Chromatography, ISO 9167-1:1992(E), Geneva, Switzerland, 1992.

[23] M. J. Morra and J. A. Kirkegaard, "Isothiocyanate release from soil-incorporated Brassica tissues," Soil Biology and Biochemistry, vol. 34, no. 11, pp. 1683-1690, 2002.

[24] V. Borek, M. J. Morra, P. D. Brown, and J. P. McCaffrey, “Transformation of the glucosinolate-derived allelochemicals allyl isothiocyanate and allylnitrile in soil," Journal of Agricultural and Food Chemistry, vol. 43, no. 7, pp. 1935-1940, 1995.

[25] P. D. Brown and M. J. Morra, "Fate of ionic thiocyanate (SCN-) in soil," Journal of Agricultural and Food Chemistry, vol. 41, no. 6, pp. 978-982, 1993. 

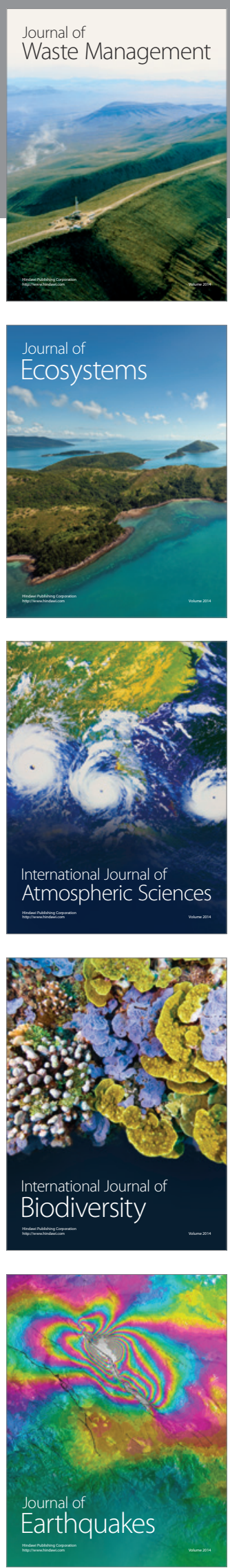
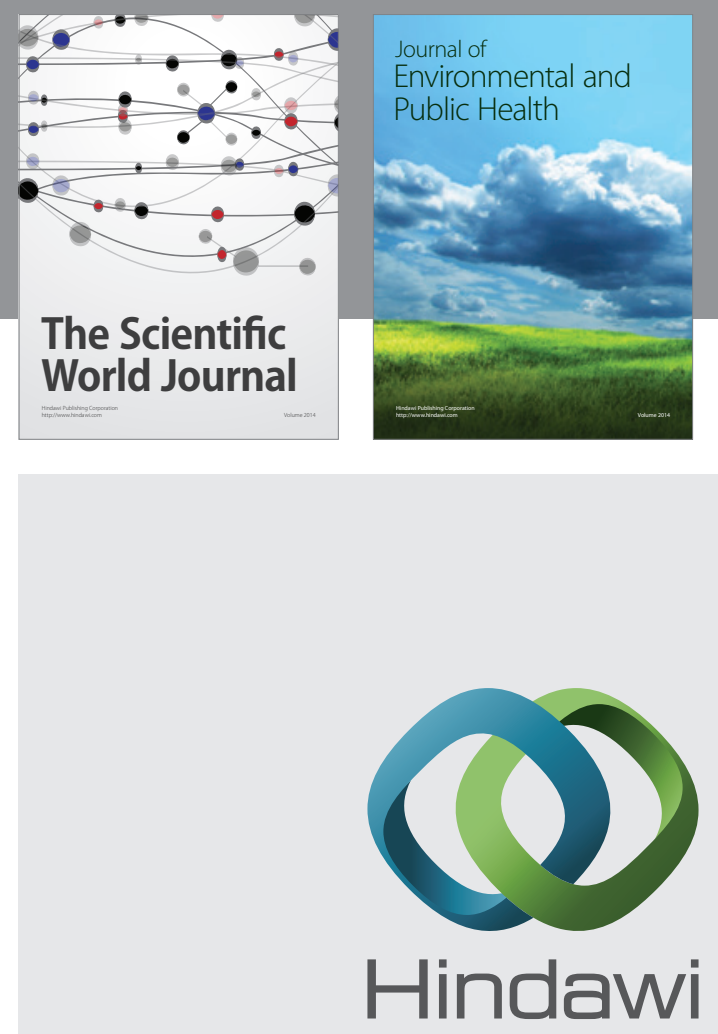

Submit your manuscripts at

http://www.hindawi.com
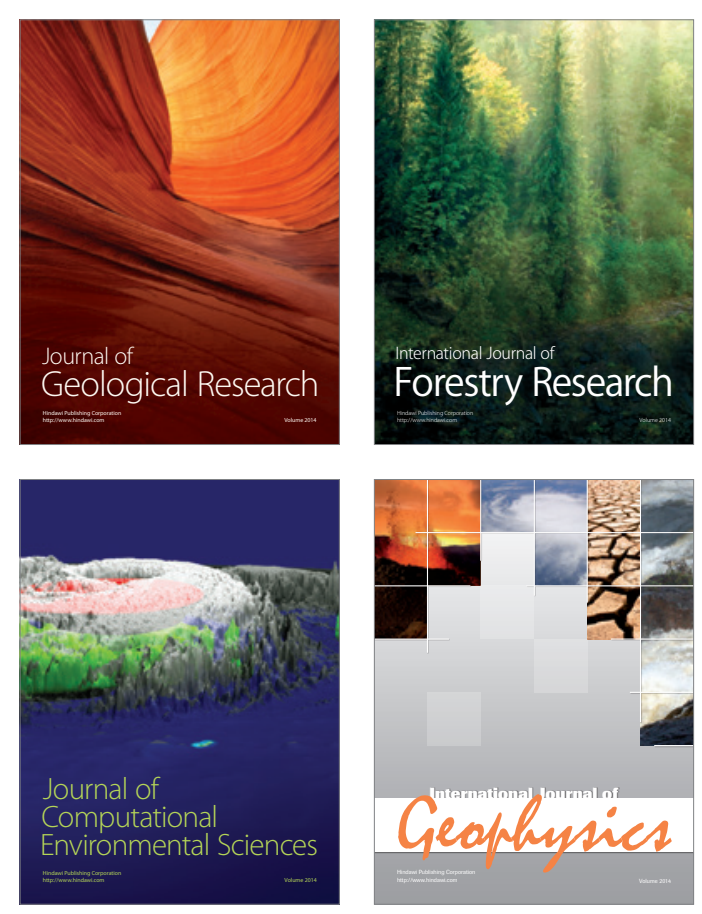
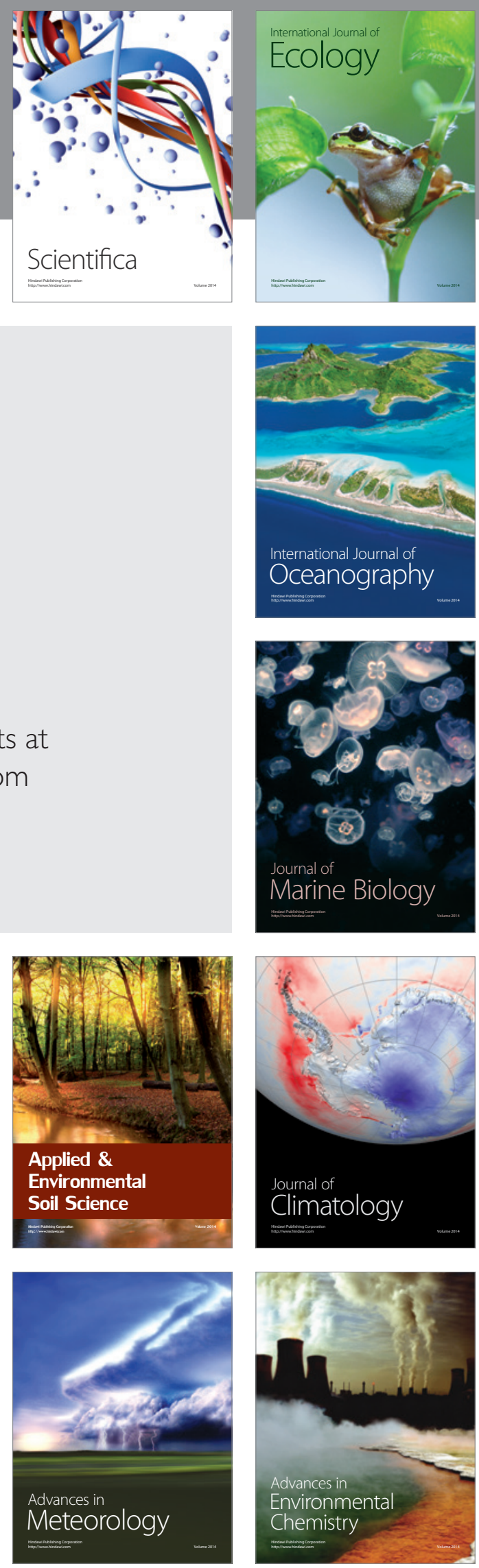